\title{
PERSPECTIVAS DAS CIDADES INTELIGENTES NA ADMINISTRAÇÃO PÚBLICA EM TEMPOS DE TRANSFORMAÇÃO DIGITAL
}

\section{PERSPECTIVES OF INTELLIGENT CITIES IN PUBLIC ADMINISTRATION IN TIMES OF DIGITAL TRANSFORMATION}

\author{
Patrícia Verônica Nunes Carvalho Sobral De Souza ${ }^{1}$ \\ Romeu Da Silva Neto ${ }^{2}$
}

\section{RESUMO}

Este trabalho tem o objetivo de desvelar as perspectivas das cidades inteligentes junto a administração pública, quanto à realidade das transformações digitais. E traz como objetivo específico realizar uma exploração bibliográfica nas bases de dados BDTD e SPELL no período de 2014 a 2020. Para tanto, este artigo utiliza-se da abordagem qualitativa, com vertentes exploratória e descritiva, de procedimentos de pesquisa bibliográfica, por meio de livros, teses e legislações pertinentes.Os resultados apontam para os desafios na implementação de inovações em tecnologias da informação e comunicação (TICs) para a criação de cidades inteligentes, proporcionando maior efetividade na gestão pública e, também, viabilizando o desenvolvimento sustentável das cidades brasileiras, com tendência a se ampliar o número de publicações científicas sobre a temática em todas as regiões do país. A principal contribuição deste trabalho é auxiliar na análise geral sobre as cidades inteligentes no Brasil, além de abrir espaço para o debate sobre a necessidade de uma visão ampla do conceito dessas cidades, no âmbito da pesquisa científica, que vão muito além da elaboração de Tecnologias da Informação e da Comunicação, apresentada neste artigo.

Palavras-chave: Administração Pùblica. Base de dados SPELL e BDTD. Cidades Inteligentes. Parcerias Público-Privadas. Transformação Digital.

\footnotetext{
${ }^{1}$ Pós-doutora e Doutora em Direito Público (UFBA). Doutora em Educação e Mestra em Direito pela Universidade Federal de Sergipe (UFS). Especialista em Direito do Estado e Especialista em Direito Municipal (UNIDERP). Especialista em Direito Civil e Processo Civil pela Universidade Tiradentes (UNIT). Especialista em Auditoria Contábil pela Universidade Federal de Sergipe (UFS). Professora titular de Graduação e Pós-graduação da Universidade Tiradentes (UNIT). Líder do Grupo de Pesquisa Direito Público, Educação Jurídica e Direitos Humanos - UNIT/CNPq. Diretora Técnica do Tribunal de Contas do Estado de Sergipe.

${ }^{2}$ Graduando em Direito, $9^{\circ}$ semestre, UNIT. Membro do Grupo de Pesquisa Direito Público, Educação Jurídica e Direitos Humanos - UNIT/CNPq.
} 


\begin{abstract}
This work aims to reveal the perspectives of smart cities with public administration, regarding the reality of digital transformations. And its specific objective is to carry out a bibliographic exploration in the databases BDTD and SPELL in the period from 2014 to 2020. For this purpose, this article uses the qualitative approach, with exploratory and descriptive aspects, of bibliographic research procedures, through books, theses and pertinent legislation. The results point to the challenges in implementing innovations in information and communication technologies (ICTs) for the creation of smart cities, providing greater effectiveness in public management and also enabling the sustainable development of Brazilian cities, with a tendency to expand the number of scientific publications on the subject in all regions of the country. The main contribution of this work is to assist in the general analysis of smart cities in Brazil, in addition to opening space for the debate on the need for a broad vision of the concept of these cities, within the scope of scientific research, which go far beyond the elaboration Information and Communication Technologies, presented in this article.
\end{abstract}

Keywords: Public administration. SPELL and BDTD database. Smart Cities. PublicPrivate Partnerships. Digital Transformation.

\title{
1. INTRODUÇÃO
}

As cidades brasileiras possuem desafios históricos de segurança, saúde, educação, saneamento básico, habitação e desigualdade social. Nesse sentido, as cidades inteligentes, sem dúvidas, devem impactar no futuro da gestão pública e influir diretamente na vida dos cidadãos. Assim, para a construção de uma cidade inteligente exige-se pensar em soluções para problemas sociais e desafios voltados à dinâmica das cidades modernas, como mobilidade, sustentabilidade e sociodiversidade, na busca de uma gestão mais efetiva, considerando ações como requalificação de áreas urbanas, iluminação e semaforização inteligente; incentivos ao desenvolvimento da economia criativa; espaços de coworking $^{3}$ e ações de incentivo a startups ${ }^{4}$; participação eletrônica; dados abertos; modernização administrativa; Centros de Controle de Operações (CCO),

\footnotetext{
${ }^{3}$ Registre-se que o coworking pode ser entendido como um modelo de trabalho que se baseia no compartilhamento de espaço e recursos de escritório, reunindo pessoas que trabalham não necessariamente para a mesma empresa ou na mesma área de atuação, podendo inclusive reunir entre os seus usuários os profissionais liberais, empreendedores e usuários independentes. (MEDINA; KRAWULSKI, 2015).

${ }^{4}$ Startups refere-se a um grupo de pessoas à procura de um modelo de negócios repetível e escalável, trabalhando em condições de extrema incerteza. (SOUZA; LOPES, 2016).
} 
monitoramento ambiental; big data ${ }^{5}$, uso de dados de celulares para políticas públicas; bicicleta pública; estrutura para carros elétricos, e muitas outras.

As cidades inteligentes representam à pública administração apenas o início de um novo conceito consubstanciado na inserção da tecnologia pelos governos municipais, o que não é uma novidade. Contudo, falta também uma visão horizontal e intersetorial na gestão das cidades para assegurar a sinergia entre as distintas áreas de políticas públicas e, daí propiciar a participação da população na construção da cidade inteligente.

O conceito de cidade inteligente, também chamadas de smart cities, é pouco conhecido pelo cidadão brasileiro. De forma simplificada, entende-se que uma cidade é inteligente quando é automatizada e possui um nível razoável de sustentabilidade objetivando a promoção de uma melhora na qualidade vida da sociedade. Assim sendo, contribuirá para aumentar a efetividade dos serviços públicos e, consequentemente, o bem-estar social. Espera, desta forma, minimizar o impacto negativo sobre o meio ambiente e, em contraponto, aumentar a transparência da gestão pública municipal. Afinal, os cidadãos associam o conceito de cidade inteligente a uma tecnologia para elaborar uma cidade eficiente, funcional, inovadora e acessível a todos.

Diante disso, este artigo tem o objetivo de desvelar as perspectivas das cidades inteligentes junto à administração pública, quanto a realidade das transformações digitais. Para demonstrar o que se objetiva transmitir, cientificamente, neste artigo, utiliza-se da abordagem qualitativa, com vertentes exploratória e descritiva, devido as relações entre as variáveis que envolvem a temática, com procedimentos de pesquisa bibliográfica, por meio de livros, teses e legislações pertinentes. E traz como questionamento: a comunidade científica brasileira tem produzido estudos sobre o tema "cidades inteligentes"?

Os cidadãos, também, esperam que a administração pública, principalmente a municipal, lidere a construção da cidade inteligente, por meio da atenção às diversas demandas que surgem nas diferentes áreas.

Nesse contexto, esta pesquisa se desenvolve ao longo de alguns momentos ou fases, por isso, delinear o caminho percorrido é importante para o alcance do objetivo deste estudo.

\footnotetext{
${ }^{5}$ Big data é o grande volume de dados, estruturados ou não, que são gerados a cada segundo e possivelmente serão cruzados, podendo gerar valor para a iniciativa privada e/ou o setor público, dentre outras atividades (SOBRAL DE SOUZA, 2019).
} 


\section{PROCEDIMENTO METODOLÓGICO}

Nesta investigação apresenta-se o levantamento e a categorização destas pesquisas, realizadas entre os meses de fevereiro a abril de 2020, relacionadas aos termos "Cidades Inteligentes" e "smart cities" contidos em produções acadêmicas publicadas no período de 2014 a 2020.

Para tal, o trabalho foi dividido em duas etapas: a) levantamento bibliográfico e b) classificação dos trabalhos em categorias.

a)Levantamento bibliográfico

Para este levantamento considerou-se como plataforma de base de dados a Biblioteca Digiral Brasileira de Teses e Dissertações (BDTD) e a Biblioteca Eletrônica de Periódicos Científicos (Spell).

Após o levantamento das pesquisas, efetuou-se a leitura dos resumos dos mesmos, para verificar a relação para com o objeto desta investigação. Estes trabalhos foram contabilizados para fins de arrolamento quantitativo. Por fim, efetuou-se a leitura completa dos estudos que atendiam a relação estabelecida com o objeto, posteriormente, classificados em categorias.

b) Classificação dos trabalhos

Terminada a leitura completa dos trabalhos, procedeu-se à classificação dos mesmos, conforme as plataformas de base de dados, em categorias: BDTD, com 321 publicações e SPELL, com 16 artigos, cujo exame sistemático possa subsidiar pesquisas futuras.

Diante disso, se torna essencial mais incentivo às pesquisas científicas quanto à tecnológia, como pré-requisito, para que as cidades inteligentes possam elaborar, dirigir e implementar políticas públicas autônomas, independentes e eficazes.

\section{AS SMART CITIES: AS CIDADES DO FUTURO}

A expressão smart cities ganha notoriedade internacional no Fórum Mundial de 1997 sobre cidades Inteligentes em que cerca de 50 mil cidades e vilas ao redor do mundo desenvolveriam iniciativas inteligentes para a próxima década (LAZZARETTI ET AL, 2019). A partir daquele fórum até os dias atuais, o foco tem sido na criatividade 
e sustentabilidade das cidades, além de uma intíma relação com a tecnologia dialogando com o uso de energia, materiais e serviços atrelados ao desenvolvimento da economia e da qualidade de vida da sociedade.

A abordagem de cidades inteligentes abrange as tecnologias, especialmente as Tecnologias de informação e comunicação, denominadas de (TICs), que viabilizam maior eficiência energética e otimização na produção de bens e serviços. Dessarte, as cidades inteligentes surgem como instrumento para a melhoria dos serviços prestados aos cidadãos, com base nas TICs que fornecem os serviços e compartilham as informações.

Nesse sentido, para Aspásia Camargo (apud FGV, 2014, p. 8):

\footnotetext{
Hoje, cidade inteligente significa cidade resiliente e sustentável, isto é, com flexibilidade e capacidade de adaptação; capaz de dar respostas rápidas e eficientes às ameaças externas, como, por exemplo, mudanças climáticas, desastres, chuvas intensas, furacões, ou, simplesmente, atender aos princípios básicos de segurança alimentar ou de qualquer outra natureza.
}

Um dos aspectos para a abordagem conceitual de cidades inteligentes corresponde ao ambiente, neste prevalece a gestão de recursos naturais por meio de ações e programas de cunho sustentável, em prol da conservação e equilíbrio do ecossistema urbano. Outro aspecto a considerar é a inovação tecnológica e de comunicação digital que correspondem às tecnologias de informação e comunicação (TICs), como instrumento de auxílio à construção do meio urbano. E ainda, refere-se ao desenvolvimento humano voltado à promoção da gestão urbana e ao cumprimento das demandas sociais, a serem implementados pelas cidades inteligentes, utilizando uma gestão transparente e o uso de ações rápidas e políticas públicas de planejamento eficientes.

Uma cidade inteligente, portanto, é uma cidade apta a elaborar estruturas de gestão eficazes para atender as demandas próprias do cenário urbano que se reproduz continuamente. Dentro desta construção conceitual, essas estruturas colocam a cidade como um sistema complexo a ser interligado por redes de comunicação, para encontrar e sanar problemas, além de determinar o trabalho humano, procurando gerar mais eficiência dos serviços públicos e, também, controlar de forma remota dispositivos e equipamentos, sem olvidar do desenvolvimento econômico e o que este pode proporcionar à coletividade (NALINI; LEVY, 2017). 
Os desafios ligados à mobilidade urbana, atualmente, são problemas para os governos, resultantes do crescimento da aquisição de automóveis e do rápido processo de urbanização ocorrido no Brasil e na América Latina. As novas populações que habitam esses centros urbanos que migraram para as cidades passaram a residir em áreas periféricas, sem infraestrutura, ocasionando cidades espraiadas e fragmentadas, pressionando bastante o setor de transportes. Entre os problemas mais encontrados estão os congestionamentos, acidentes de trânsito, poluição do ar, sonora,além de alterações climáticas (UN-HABITAT, 2013).

Para minimizar tais impactos negativos na sociedade, o conceito de cidade inteligente surge como ferramenta de solução desses problemas, através, por exemplo, do fornecimento de energia, gestão de resíduos e transporte (mobilidade), por meio da maior eficiência de utilização de recursos (CALVILLO; SÁNCHEZ-MIRALLES; VILLAR, 2016).

A busca pela sustentabilidade, inteligência, resiliência ${ }^{6}$ e responsividade $^{7}$ utiliza um conjunto de novas Tecnologias de Informação e Comunicação (hardware $e$ software), aptas em modificar a elaboração e controle da infraestrutura e dos serviços urbanos, beneficiando, desta forma, a gestão pública das cidades em atender às demandas da coletividade. Dessa forma, por meio de sistemas de informação complexos e dinâmicos, as TICs integram um rol de tecnologias que habilitam o conceito de cidades inteligentes, uma vez que interagem diretamente com a população e, consequentemente, viabiliza a responsividade para os serviços urbanos.

O contexto de cidades inteligentes torna o modelo de novas tecnologias juntamente ao uso de $M 2 M^{8}$ (Machine to Machine), IoT ${ }^{9}$ (Internet of Thing) e IoE (Internet of Eferything) assente em uma economia criativa, através de sua realização pelos governos (JORDÃO, 2016).

\footnotetext{
${ }^{6}$ Para Manso (2020, p. 24) e de acordo com a Norma ISSO 37101/2018, a resiliência é a "capacidade adaptativa de uma organização em um ambiente complexo e mutável".

${ }^{7}$ Responsividade é definida "como conceito de ciência de computação refere-se à capacidade de um sistema ou unidade funcional de completar tarefas atribuídas de um determinado tempo" (WEIK ipud MANSO, 2020, p.24).

${ }^{8}$ Machine to Machine é quando as máquinas utilizam a rede para se comunicarem remotamente com essa estrutura integrada, monitorarem e controlarem sem necessitar da participação humana, mesmo que o foco desse monitoramento ou controle seja o ambiente ou a própria máquina (COLOMBO; LUCCA FILHO, 2018).

${ }^{9}$ Internet of Thing é uma tendência tecnológica de utilização de dispositivos inteligentes conectados e interagidos para elaborar uma rede integrada de monitoramento, no qual todos os dados são cruzados e estão à disposição do gestor tecnológico (COLOMBO; LUCCA FILHO, 2018).
} 
O que existe é uma tríade: inovação-cidade-tecnologia que ultrapassa limites, influindo diretamente no conceito de cidade inteligente (smart cities). Anteriormente apenas se remetia a um uso mínimo da tecnologia na gestão urbana e, atualmente, a sustentabilidade ambiental ganhou força dando-se maior atenção ao impacto urbano e ao seu desenvolvimento. Dessa forma, tem-se a associação do sustentável à cidade inteligentes em prol do desenvolvimento local .

O estágio de evolução de cada cidade difere-se consoante o seu ponto de partida, bem como das demandas sociais locais. Diante disso, pode-se, inclusive, destacar quatro estágios de evolução para a implantação de uma cidade inteligente, conforme ensina (DELOITTE, 2019). Esses estágios são: Vertical, se aplica a tecnologia aos serviços urbanos para melhorar sua gestão; Horizontal, se desenvolve uma plataforma de gestão transversal dos diferentes serviços; Conecntado, os diversos serviços verticais interconectam-se e começam a operar em uma plataforma de gestão e Inteligente em que se gerencia a cidade de forma integrada e em tempo real, e se oferece informação e serviços de alto valor agregado a cidadãos e empresas. Todas estas fases se baseiam na inteligência compartilhada por todos os atores da cidade sendo a plataforma da cidade um facilitador das soluções colaborativas (DELOITTE, 2019).

Para conseguir avançar nos estágios de implementação de cidades inteligentes, é necessário superar diferentes barreiras. As principais críticas a essa nova modalidade de cidade é a centralização de seus moradores em periferias por conta do aumento do aluguel através da AirBnB e a incerteza de vínculo empregatício nos serviços prestados pelos aplicativos Uber, Rappi, iFood e etc. Cada cidade obterá seu conjunto próprio de desafios, envolvendo a sua identidade, história, geografia e cultura. Todavia, pode-se identificar um rol de problemas comuns. Existem seis frentes de trabalho para passar da estratégia à execução. São elas: liderança, visão, relações público-privado, solução tecnológica, financiamento e modelos de negócios (DELOITTE, 2019).

Cumpre registrar que estas etapas devem estar bem delineadas e solidamente amarradas, cada uma no seu âmbito de atuação. Estas frentes de trabalho são apontadas pelos especialistas como essenciais para passarem da estratégia para a execução da implantação das cidades inteligentes, como adiante se verá.

\subsection{Frentes de trabalho para a execução das Cidades Inteligentes}


Diante do evidenciado no tópico acima, a liderança prescreve uma gestão com capacidade de execução e visão transversal das ações definidas. Logo, a figura do prefeito ou chefe do executivo deve ter uma liderança essencial no percurso, definindo a agenda e alocando os recursos (CUNHA, 2016).

Sobre o tema Alfonso Vegara (2014, p. 42) assevera que:

Os Territórios Inteligentes desenham seu futuro através da liderança, da participação da população e mediante processos que garantam a inovação. São, portanto, territórios com uma forte liderança, uma sociedade civil madura e uma notória coesão interinstitucional. Nesse contexto, observa-se uma liderança política coerente, que pressupõe uma vantagem competitiva significativa para a cidade.

Além disso, deve-se viabilizar uma gestão mais transversal que possibilite as sinergias entre os serviços, além de uma gestão pautada nas demandas sociais, que se sustente para além do tempo de uma gestão municipal.

Sem dúvidas, as cidades vêm adotando algumas iniciativas em diversos temas como meio ambiente, mobilidade e economia. As iniciativas, como já dito, são variadas, e delas submetem-se diferentes modelos, que possuem prioridades e causas múltiplas. Assim, a cidade possui seus problemas específicos e se encontram em diferenciados níveis de desenvolvimento social e econômico. Por tal contexto, os especialistas corroboram o mesmo entendimento de que cada cidade deve ter tratamento singular.

Por sua vez, para que a etapa da visão seja implementada, se faz necessário o seu compartilhamento por todos os sujeitos envolvidos, na medida em que as cidades são consideradas ecossistemas complexos, nos quais seus agentes e sua população possuem seus próprios anseios (CUNHA, 2016).

Para concretizar a visão de cada cidade em sua unidade, a administração local deve observar os seguintes aspectos: a) priorizar o cidadão; b) compreender que o contexto econômico é fonte essencial para a estratégia das cidades inteligentes no Brasil; c) enfrentar os antigos e novos desafios; e, d) compreender que a tecnologia serve como meio de empreender a transformação (CUNHA, 2016).

De tal modo, ressalte-se que a população deve sempre estar no foco central, colaborando e participando ativamente desse processo.

Quer-se, na frente das relações público-privadas, ir além do modelo atual, baseado em um volume fixo de recursos para a prestação de cada serviço. Devendo-se 
determinar um novo modelo de relações entre a administração pública e as empresas, por meio de um marco legal facilitador da integração dos serviços, do desenvolvimento de formas de relacionamento de longo prazo, da incorporação de "pagamento por serviço" com base em métricas de resultados (CUNHA, 2016).

Já a solução tecnológica traz a necessidade de uma flexibilidade da integração dos sistemas setoriais em uma plataforma para a gestão da cidade. Evidente se torna a necessidade de se incorporar uma solução tecnológica aberta e padronizada, horizontal, Inter operável e com escalabilidade (CUNHA, 2016).

Estruturar também modelos de financiamento com a participação privada, por meio de um avanço mais rápido na melhoria dos serviços e incorporação de capacidades e conhecimentos que os municípios podem não possuir (CUNHA, 2016).

É de se considerar que os modelos de negócios sustentáveis, por seu turno, trazem benefícios para todos os agentes envolvidos. O que se almeja é auferir os benefícios de uma cidade inteligente sobre os diferentes serviços que a constituam e se mantenham por um longo prazo. Ciente de que as plataformas de cidade inteligente produzem informações que viabilizam a evolução dos modelos de negócios em duas direções, que se bipartem: a) na melhora da gestão municipal por conta dos serviços gerenciados com base em indicadores de utilização, sendo estes de qualidade ou de economia de recursos, para maior rendimento e retorno sobre o investimento; b) na disponibilização de informações a terceiros, por meio dos conhecidos "dados abertos", para a elaboração de modelos baseados na economia colaborativa e no empreendedorismo. É a economia baseada nos dados (economy of data) (CUNHA, 2016).

Cumpre destacar que cabe a cada cidade desenvolver seu próprio processo até atingir todas as etapas a fim de se alcançar uma gestão inteligente. Mas, para a efetivação dessa nova gestão, é preciso a implementação da liderança adequada em conjunto com os demais setores da Administração Pública, bem como com as empresas, com as universidades e com a população.

\subsection{Fatores que demandam atenção para a execução das Cidades Inteligentes}

Indubitavelmente, a urbanização desordenada resulta num crescimento populacional que produz um rol de problemas sociais nas cidades, como a violência, o 
desemprego e a exclusão social. Nesse passo, emergem questões/problemas quanto a acessibilidade, principalmente em decorrência do aumento da conscientização das pessoas em relação a igualdade de direitos.

O uso da tecnologia fornece uma revisão desse problema, ajudando não apenas em questões como a acessibilidade, mas, também, na tomada de decisões pautadas em cidades mais humanas e inteligentes. A partir dessa conjuntura, este trabalho tem como condão construir um pensamento crítico/reflexivo no leitor quanto a importância do uso da tecnologia para mitigar o problema e propagar informações sobre acessibilidade. Os fundamentos são baseados em conceitos de crowdsensing ${ }^{10}$ e cidades inteligentes e usam o método de pesquisa de design. As técnicas de coleta de dados incluem questionários fechados, entrevistas e dados iconográficos. Como resultado, sugere-se o uso de aplicativos que podem ser usados em computador ou smartphone, ativa ou passivamente (ALPERSTEDT NETO, ROLT, ALPERSTEDT, 2018).

O Brasil, segundo o ranking do IESE Business School ${ }^{11}$ de 2019, ocupa 6 posições. São elas: Brasília - 130a ; São Paulo - 132 ; Rio de Janeiro - 128 ; Curitiba $140^{\mathrm{a}}$; Salvador - $146^{\mathrm{a}}$; e, Belo Horizonte $-151^{\mathrm{a}}$. Os maiores destaques são investimentos em mobilidade urbana através de ciclovias e corredores de ônibus, criação do Ecoelétrico - frota de carros elétricos que fornecem serviços públicos -, investimento em tecnologia para melhoria da mobilidade urbana e produção de energia (IESE BUSINESS SCHOOL, 2019).

Novas tecnologias podem auxiliar na locomoção e na redução de problemas sociais (ALPERSTEDT NETO; ROLT; ALPERSTEDT, 2018), como: os aplicativos de versão móvel dos bancos — resolvem os problemas de pessoas com mobilidade reduzida que sofrem indo ao banco pela má instalação urbana e com a chegada desses aplicativos não há mais a necessidade da presença física no banco.

\footnotetext{
10 Trata-se de uma técnica em que um grande grupo de indivíduos com dispositivos móveis capazes de detectar e computar (como smartphones, tablets, wearables) compartilham coletivamente dados e extraem informações para medir, mapear, analisar, estimar ou inferir (prever) qualquer processo de interesse comum.

${ }^{11}$ A IESE Business School é a escola de pós-gradução em Administração de Empresa da Universidade de Navarra e possui programas de educação a distância. Atualmente é considerada uma das escolas de negócios mais importantes em todo o mundo, conhecida por seus programas de MBA e "Executive MBA". Ela dispõe de programas "Global Executive MBA" e do doutorado em Administração de Empresas no nível de $\mathrm{PhD}$, bem como programas para executivos. Convém esclarecer, igualmente, que o papel destas escolas de negócios converge para desenvolver e inspirar líderes empresariais que se esforçam para causar um impacto profundo, positivo e duradouro nas pessoas, empresas e na sociedade a que servem.
} 
Além disso, por meio da tecnologia, surge a possibilidade de aprimorar a infraestrutura de espaços públicos, para, destarte, ampliar a autonomia e facilitar a vida cotidiana das pessoas com deficiência.

\subsection{Legislação e políticas públicas brasileiras}

A Emenda Constitucional $n^{\circ}$ 85/2015 promoveu novas disposições ao capítulo IV da Constituição Federal de 1988, que trata da ciência, tecnologia e inovação em capítulo próprio, dentro do título referente à ordem social.

Em decorrência disto, reforça-se a valorização do tema, dando especial atenção à inovação, promovendo-se uma nova perspectiva para o desenvolvimento econômico do país. Para o art. 218 "O Estado promoverá e incentivará o desenvolvimento científico, a pesquisa, a capacitação científica e tecnológica e a inovação.” (BRASIL, 1988)

Para tanto, a emenda buscou expandir as possibilidades de apoio financeiro do poder público nestas áreas, entre as mais relevantes, conforme preceitua o art. $213, \S 2^{\circ}$, "as atividades de pesquisa, de extensão e de estímulo e fomento à inovação realizadas por universidades e/ou por instituições de educação profissional e tecnológica" (BRASIL, 1988).

Entretanto, é sabido que no Brasil há milhões de cidadãos que nunca, até então, acessaram um computador ou a internet. Constata-se daí uma privação de oportunidades para este grupo, quanto ao trabalho, ao acesso a novas culturas e formas de cidadania, na medida que são exigidas capacidades/habilidades inovadoras na Sociedade Informacional.

Vale destacar que, a nível nacional, a quinta edição do Ranking Connected Smart Cities ${ }^{12}$, divulgou em 2019, as dez cidades mais inteligentes do Brasil: $1^{\circ}$ Campinas-SP; $2^{\circ}$ São Paulo-SP; $3^{\circ}$ Curitiba-PR; $4^{\circ}$ Brasília-DF; $5^{\circ}$ São Caetano do Sul; $6^{\circ}$ Santos-SP; $7^{\circ}$ Florianópolis-SC; $8^{\circ}$ Vitória-ES; $9^{\circ}$ Blumenau-SC e $10^{\circ}$ Jundiaí-SP. Um fato que marca essa lista é que, pela primeira vez, o Ranking Connected Smart Cities, escolheu uma cidade do interior, não sendo a capital, como maior referência em desenvolvimento: Campinas, maior cidade do interior de São Paulo foi considerada a mais inteligente e conectada do Brasil em 2019 (BRAZILLAB, 2019).

\footnotetext{
${ }^{12}$ Ver lista completa em: https://infogram.com/ranking-1hkv2n89e5jz2x3,
} 
Ainda segundo o Ranking Connected Smart Cities, a primeira cidade do nordeste a aparecer na lista é Recife, ocupando a $23^{\mathrm{a}}$ colocação de referência em tecnologia e inovação. Recife detaca-se por possuir 14,9\% das conexões de internet com velocidade superior a $34 \mathrm{mb}$, além de possuir cobertura $4 \mathrm{G}$ oferecida por quatro empresas e $27,7 \%$ dos empregos formais exercidos por profissionais de nível superior. Ainda na região nordeste. Teresina recebe a $4^{a}$ posição no Ranking Nordeste Connected Smart Cities por possuir 41,9km de ciclovias, conectividade entre o Aeroporto e o Terminal Rodoviário com rotas que ligam a cidade a mais de 163 destinos interestaduais e existência de metro (CONNECTED SMART CITIES, 2018).

Por outro lado, pode-se citar, como exemplo também, as iniciativas da cidade de Porto Alegre, $20^{\mathrm{a}}$ posição no ranking, relativo à materialização do conceito de cidade inteligente. A cidade implementou inovações em tecnologias da informação e comunicação (TICs) na prestação dos serviços públicos proporcionando maior eficiência nas atividades que envolvem a gestão da cidade. Destaque-se que, desde 2006, Porto Alegre vem tomando medidas para tornar a cidade mais dinâmica, assegurando o desenvolvimento urbano conduzido pelos negócios, inclusão social de vários residentes urbanos, sustentabilidade social e ambiental, etc., como por exemplo, a implantação de uma rede de fibras óticas, garantindo o acesso de alta velocidade à internet (155Mbps) e conectando mais de 12 mil computadores nos diversos órgãos públicos; na educação, a iniciativa partiu do projeto Wireless Educação, com investimentos de R \$ 2 milhões, contemplando a instalação de conexão sem fio de alta velocidade à internet na rede de ensino. $\mathrm{Na}$ saúde, merece destaque o Sistema Telemedicina, criado em 2008, possibilitando às gestantes a realização de exames de ultrassonografias nos postos de saúde e outros (WEISS; BERNARDES; CONSONI, 2015).

Pensar na efetivação do conceito de cidades inteligentes é produzir ações diretas na qualidade de vida das pessoas por meio da tecnologia levando em consideração as novas economias, economia criativa, economia compartilhada, economia circular, etc., trazendo resiliência, inclusão e acessibilidade para seu território.

A seguir, são apresentados os resultados encontrados por meio da pesquisa bibliográfica nas plataformas de dados Biblioteca Digital Brasileira de Teses e Dissertações (BDTD) e Scientific Periodicals Electronic Library- SPELL. 


\subsection{Pesquisa nas bases de dados da Biblioteca Digital Brasileira de Teses e Dissertações (BDTD) e Scientific Periodicals Electronic Library (SPELL)}

A partir da expressão de busca "cidades inteligentes" na Biblioteca Digital Brasileira de Teses e Dissertações (BDTD), encontrou-se um total de 321 pesquisas, sendo 258 dissertações (80\%) e 63 teses (20\%). Sublinha-se que, por meio da expressão "smart cities" obteve-se 35 estudos e "smart city" 8 trabalhos. A área de maior concentração foi a de ciências sociais e aplicadas e, dentre elas, Administração, com 40 investigações. No que se refere a instituição de origem dos trabalhos tem-se que 54 são oriundos da Universidade de São Paulo (USP), instituição pública e 34 da Universidade Nove de Julho (UNINOVE), instituição privada, o que significa um interesse maior pelo tema na região sudeste e pelas universidades públicas.

O levantamento feito junto à plataforma de base de dados Scientific Periodicals Electronic Library (SPELL) apresentou um total de 16 artigos, sendo que 7 estudos estavam voltados para a área de administração, 3 para área de ciência da computação, 1 para área de economia, 1 para área de arquitetura e urbanismo, 1 para área de cidade digital estratégica, 1 ciências ambientais, 1 para área de contabilidade e 1 voltado para a área de antropologia social, como abaixo especificados:

Tabela 1: Artigos encontrados na base de dados Spell: período 2014 a 2020

\begin{tabular}{l}
\hline 1-Aplicação WEB para Indicadores de Cidades do Conhecimento ID: 55725 \\
Autoria: Daniel Luis Notari, Rafael Battistelo, Lucas Webber Molin, Scheila de Avila e Silva, Ana Cristina \\
Fachinelli. \\
\hline 2-O Uso de Tecnologias como Estratégia na Construção de Cidades mais Inteligentes e Sustentáveis \\
ID: 53958 \\
Autoria: Paola Pol Saraiva, Inara Pagnussat Camara, Lauro André Ribeiro, Thaísa Leal da Silva. \\
\hline 3-Utilização do Conceito de Cidades Inteligentes para Repensar os Processos de Comunicação dos \\
Conselhos Municipais ID: 56731 \\
Autoria: Thiago Ferreira Quilice, Cleiton Martins Duarte da Silva, Naraiana Marques Jácome, Poliana \\
Estefane Sanches. \\
\hline 4-Coprodução Sociedade Civil - Governo na Constituição de Cidades Inteligentes no Estado do Pará \\
ID: 54686 \\
Autoria: Mauro Margalho Coutinho, Mário Vasconcellos Sobrinho, Ana Margarida Santiago, Sue Anne \\
Collares Maestri de Oliveira. \\
\hline 5-Cidades Inteligentes: Uma Visão sobre a Agenda de Pesquisas em Tecnologia da Informação \\
ID: 53417 \\
Autoria: Marcos Cesar Weiss \\
6-Indicadores para Cidades Inteligentes: A Emergência de um Novo Clichê ID: 55250 \\
\hline
\end{tabular}




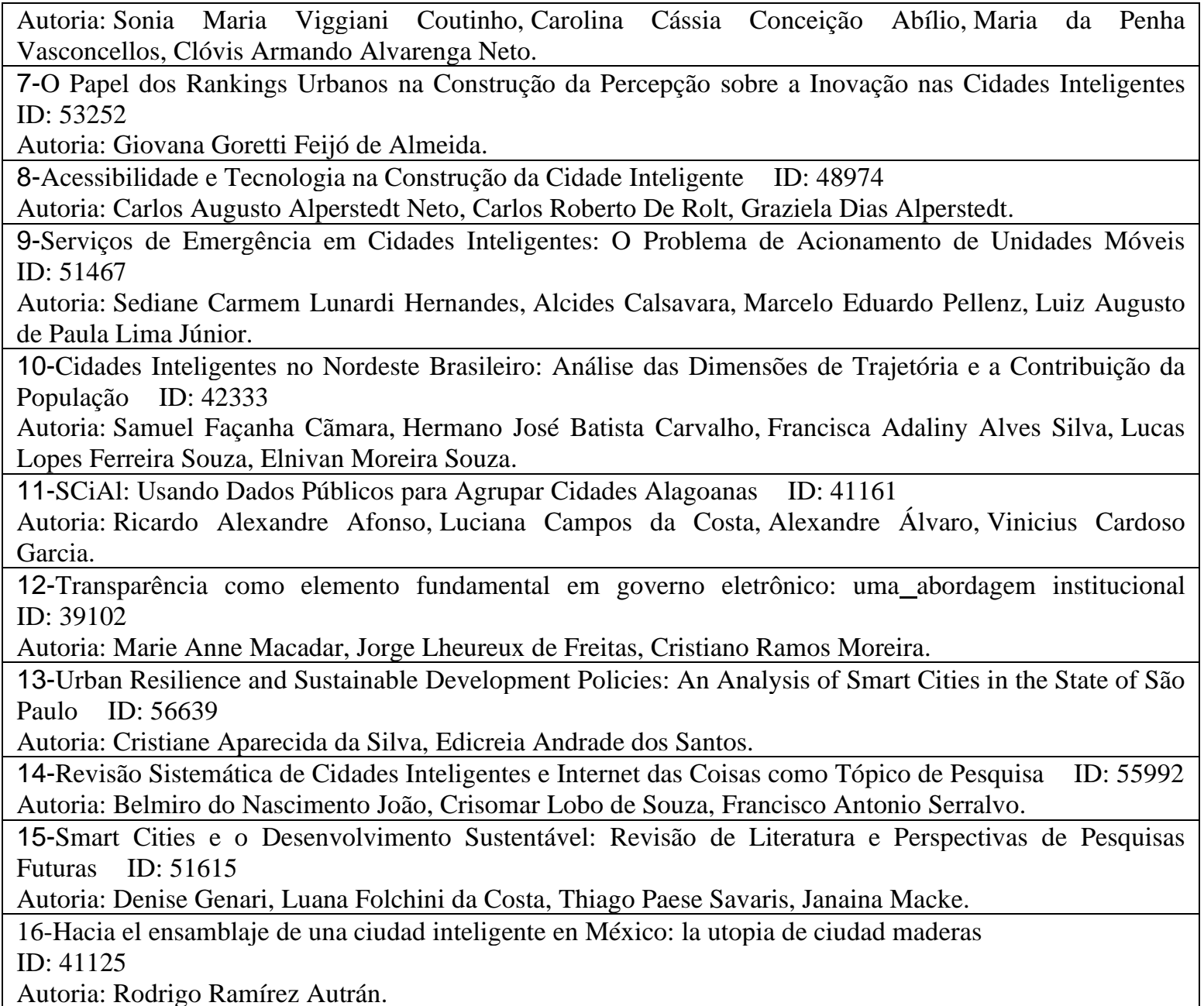

Fonte: Elaborado pelos autores, 2020.

A maior parte da produção destas pesquisas foi realizada no ano de 2019, representando 37,5\%, no ano de 2018 o percentual foi 25\%. Nos anos de 2020, 2017, 2015 e 2014 houve $6,25 \%$ para cada e no ano de 2016 o resultado apontou 12,5\%, como mostra o gráfico 1 abaixo.

Gráfico 1: Distribuição da quantidade de trabalhos encontrados por ano. 


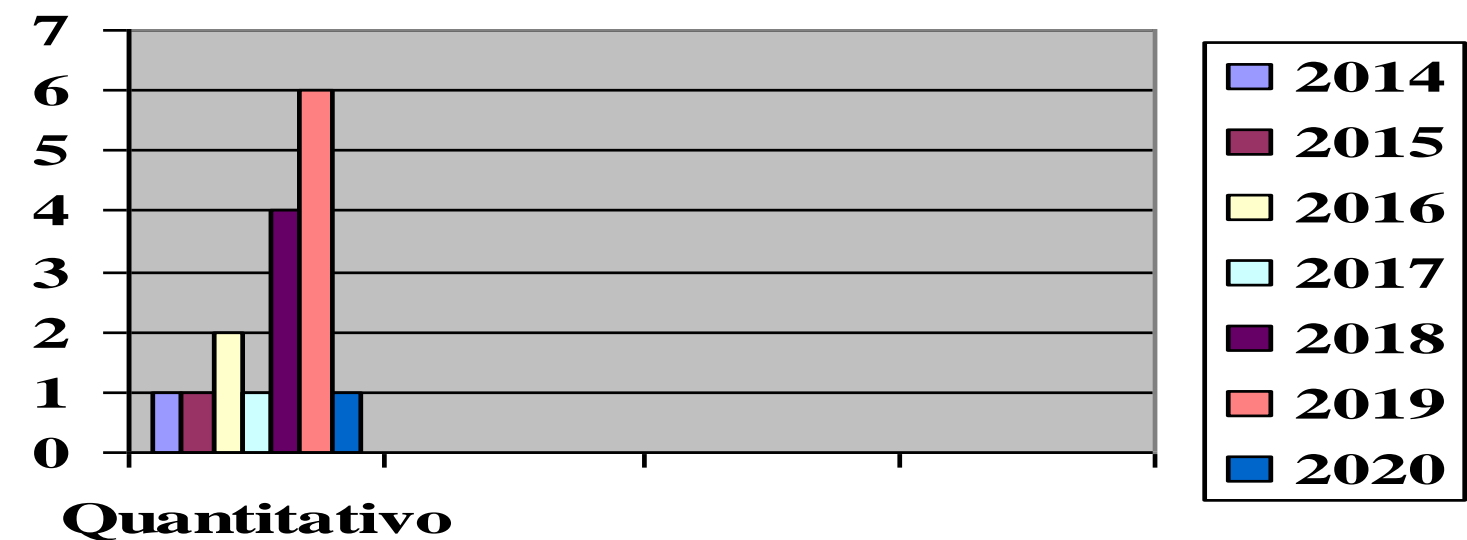

Fonte: Elaborado pelos autores, 2020.

De acordo com os resultados, é possível perceber a vinculação institucional com os respectivos autores (as). Nessa perspectiva, foram 16 instituições, sendo a Pontifícia Universidade Católica (PUC) a que apresentou maior número de trabalhos publicados com autores (as) vinculados (as) a ela, representando 25\%, como mostra a tabela 2 abaixo:

Tabela 2: Instituição de ensino vinculada com os autores (as).

\begin{tabular}{|l|l|l|}
\hline Instituição & Quantidade & \multirow{2}{*}{$\%$} \\
\hline Pontifícia Universidade Católica de São Paulo (PUC-SP) & 1 & \multirow{2}{*}{$25 \%$} \\
\hline Pontifícia Universidade Católica do Rio Grande do Sul (PUCRS) & 2 & \\
\hline Pontifícia Universidade Católica do Paraná (PUCPR) & 1 & $6,25 \%$ \\
\hline Centro Investigaciones Infotec & 1 & $6,25 \%$ \\
\hline Universidade Federal de Santa Catarina (UFSC) & 1 & $6,25 \%$ \\
\hline Universidade Federal de Alagoas (UFAL) & 1 & $6,25 \%$ \\
\hline Universidade Estadual do Ceará (UFC) & 1 & $6,25 \%$ \\
\hline Universidade Caxias do Sul (UCS) & 1 & $6,25 \%$ \\
\hline Universidade do Amazonas (UFAM) & 1 & $6,25 \%$ \\
\hline Escola Superior de Propaganda e Marketing (ESPM) & 1 & $6,25 \%$ \\
\hline Instituto de Estudos Avançados IEA (USP) & 1 & $6,25 \%$ \\
\hline Universidade do Estado de Santa Catarina (UDESC) & $6,25 \%$ \\
\hline $\begin{array}{l}\text { Instituto Federal de Educação, Ciência e Tecnologia do Rio Grande do } \\
\text { Sul }\end{array}$ & 1 & \\
\hline Universidade de Passo Fundo (UPF) & 1 & $6,25 \%$ \\
\hline Universidade de São Paulo (USP) & 1 & $6,25 \%$ \\
\hline
\end{tabular}

Fonte: Elaborada pelos autores, 2020.

Os dados apontam também para uma hegemonia das pesquisas na região sul com 8 artigos (50\%) e sudeste com 4 trabalhos (25\%). Na região nordeste tem-se 2 artigos $(12,5 \%)$ e na região norte 1 trabalho $(6,25 \%)$. Some-se aos trabalhos acima, o de uma instituição pública mexicana, Centro Investigaciones Infotec. Esses dados indicam a necessidade de projetos de pesquisas nas outras regiões do Brasil para fomentar o uso 
de tecnologias, melhorar a estrutura, otimizar a mobilidade urbana, criar soluções sustentáveis e tornar as cidades mais acessivéis a todos, características fundamentais de cidades inteligentes compromissadas também com a administração pública.

\section{AS CIDADES INTELIGENTES E A ADMINISTRAÇÃO PÚBLICA}

Bandeira de Mello (2014, p. 687) define serviço público como "uma utilidade ou comodidade material fruível singularmente, mas que satisfaz necessidades coletivas que o Estado assume como tarefa sua, podendo prestar de forma direta ou indireta, seguindo regime jurídico de direito público". Deste modo, o Poder Público como guardião dos interesses coletivos, tem que bem planejar e proporcionar melhores serviços públicos à sociedade, nos moldes da Lei de concessão e permissão de serviços públicos, coadunando-os com os princípios da transparência, da eficiência, da generalidade $^{13}$, da atualidade ${ }^{14}$, da sustentabilidade, da segurança, da cortesia e da continuidade, elementos essenciais do sistema de compliance ${ }^{15}$, no qual se submete a própria administração pública quanto ao cumprimento das normas legais e regulamentares externas.

Tendo em vista o grande uso das Tecnologias da Informação e Comunicação (TIC) atualmente, e percebendo sua gradual participação nas diversas esferas de governo, a fim de se implementar as cidades inteligentes, deve-se propor uma agenda para a pesquisa no uso e nas implicações sociais das Tecnologias de Informação e Comunicação pelos governos no Brasil.

As tecnologias da informação e comunicação são consideradas entre os mais importantes tópicos na era digital. Novos serviços, empresas, startups surgem mudando o caminho das empresas estabelecidas que dirigem o mercado.

Nessa toada, cabe versar sobre a contribuição da inteligência artificial, que é considerada a área da ciência computacional que trata do desenvolvimento de

\footnotetext{
${ }^{13}$ A generalidade significa que a prestação do serviço público deve ser estendida a maior quantidade possível de usuários.

${ }^{14}$ A atualidade é estipulada no art. $6^{\circ}$, $\S 2^{\circ}$, da Lei n. 8.987/95 como sendo a modernidade das técnicas, dos equipamentos e das instalações e a sua conservação, bem como a melhoria e expansão do serviço.

${ }^{15}$ Consiste em estar em conformidade com leis e regulamentos (internos e externos); ou seja, atender às leis e aos normativos dos órgãos reguladores e também aos regulamentos internos da empresa, aos princípios éticos da sociedade, em especial os relacionados aos seus controles internos e governança. (MAKISHI, 2019).
} 
computadores e máquinas que possuem capacidade de imitar o homem (GABRIEL, 2018).

As tecnologias trazem um ponto de vista perturbador para os modelos de negócios e tarefas diárias. Essas mudanças exigem a adaptação de mercados, empresas e governo. Desta forma, muito esforço está sendo feito pelos governos para adaptar e incorporar novas tecnologias para digitalizar o mundo.

Castells (2012, p. 82) preleciona que:

Quando, mais tarde, a tecnologia digital permitiu o empacotamento de todos os tipos de rnensagens, inclusive de som, imagens e dados, criou-se uma rede que era capaz de comunicar seus nós sem usar centros de controles. A universalidade da linguagem digital e a pura lógica das redes do sistema de comunicação geraram as condições tecnológicas para a comunicação global horizontal.

Sem dúvidas, é um desafio que não se limita apenas à intervenção do governo. Tanto os cidadãos quanto as empresas assumem uma posição de suma relevância neste contexto de transformações para um ambiente digital, incentivando a expansão das Tecnologias de Informação e Comunicação nas cidades.

Especificamente no Brasil, o governo tem realizado vários estudos e já gerou alguns relatórios levando em consideração os desafios e lacunas que precisam ser abordados para melhorar o mercado de Tecnologias e impulsionar o país em direção a uma estratégia digital. Associações e outras entidades relacionadas ao mercado de Tecnologia também tem motivando o mercado brasileiro.

Outro ponto a se destacar sobre as tecnologias é a viabilização da acessibilidade das pessoas idosas e com deficiência beneficiadas pela acessibilidade implantada nas cidades inteligentes, por meio da "conectividade, rede de sensores, computação em nuvem, Big Data, recursos colaborativos, isto é, informações originadas pelos indivíduos" (TELLES; BARBOSA; RIGHI, 2017, p. 2). A Lei Brasileira de Inclusão, ${ }^{16}$ tutela condições de igualdade, exercícios de direitos e de liberdades fundamentais por pessoas com deficiência ${ }^{17}$, visando a sua inclusão social e cidadania.

\footnotetext{
${ }^{16}$ Lei nº13.146, de 6 de julho de 2015. Disponível em: http://www.planalto.gov.br/ccivil_03/_ato20152018/2015/lei/113146.htm. Acesso em 5 Abr. 2019.

17 A PEC 25/2017 alterou dez artigos da Constituição com expressões antigas que já não mais se sustentavam diante do amadurecimento do tema, como "pessoa portadora de deficiência" ou "portador de deficiência" por "pessoa com deficiência", utilizada pela Convenção Internacional sobre o Direito das Pessoas com Deficiência. (BRASIL, 2017).
} 
Para oportunizar a efetiva concretização das smart cities no planejamento urbano, faz-se mister o ajustamento da perspectiva das cidades inteligentes ao desenvolvimento das ações sociais da cidade, sendo fundamental o envolvimento da população no processo de inovação urbana, incluindo a priorização das atividades direcionadas ao combate e a redução das desigualdades sociais e territoriais, para eliminar a pobreza, implementar a justiça social e atender aos direitos fundamentais das pessoas (LIBÓRIO; SAULE JÚNIOR, 2017).

Existem muitas lacunas entre oferta e demanda de habilidades em diferentes setores no Brasil. Os desafios dos setores de TIC, a falta de orientação política adequada e o ritmo lento no desenvolvimento do capital humano causaram um aumento no número de lacunas existentes.

O governo brasileiro, no entanto, vem fazendo esforços para mudar a situação atual. Por exemplo, o programa "Brasil Eficiente" criou o Conselho Nacional de Desburocratização para tratar diretrizes e asserções para simplificar e modernizar a administração pública, bem como melhorar os serviços públicos à sociedade, classificando prioridades e metas para a desburocratização, previstas em 8 programas, incluindo o da estratégia digital brasileira, que estrutura os principais objetivos para as novas versões da Estratégia de Governança Digital (Governança Digital - EGD).

A "governança eletrônica" - também conhecida como $e$-governança ${ }^{18}$, é dividida em três subtemas: a) e-administração; b) e-serviços públicos; e c) e-democracia.

De acordo com os ensinamentos de Cunha e Miranda (2013), a $e$-administração é o conceito tecnológico (digital) mais antigo e mais conhecido na esfera do setor público, na medida em que são implementados diversos projetos elaborados na Administração Pública brasileira, seja na área de gestão, bem como na área de políticas públicas, tudo auxiliado pela ferramenta tecnológica. Portanto, a $e$-administração importa na melhoria das atividades da máquina pública, por meio das tecnologias de informação e comunicação (CUNHA; MIRANDA, 2013).

Por outro lado, os considerados $e$-serviços, são definidos como a prestação de serviços através de portais digitais, governamentais e das centrais de atendimento. Esta nova modalidade resulta em uma maior efetividade na prestação de serviços à população, fornecendo-lhe mais métodos de atendimento.

\footnotetext{
${ }^{18}$ Corresponde ao exercício de autoridade política, econômica e administrativa nos assuntos de um país, incluindo a articulação dos cidadãos para a defesa de seus interesses e o exercício de seus direitos e obrigações (UNESCO, online).
} 
Além disso, existe a $e$-democracia que importa na ampliação democrática por meio do uso das tecnologias de informação e comunicação (CUNHA; MIRANDA, 2013). Isto é, o $e$-democracia fomenta o poder de participação do cidadão.

Dessa forma, as TICs facilitam a comunicação entre Estado e cidadão e principalmente com os participantes políticos, expandido a capacidade democrática dos indivíduos. Por conseguinte, ao pensar o desenvolvimento das cidades é de se incluir a população com seus territórios, os governos, as tecnologias, as infraestruturas e os recursos naturais. A ligação entre estes elementos possibilita uma maior aproximação, permitindo decisões e ações para tornar as cidades mais inteligentes, a partir de suas potencialidades e características.

Nesse interim, para a participação de todos no processo democrático eletrônico, por exemplo, se torna necessária a adoção de infraestrutura adequada, além de conhecimento suficiente para manusear todo o equipamento. Caso contrário, ocasionaria desigualdades e, logo, o que poderia ser um mecanismo benéfico para os cidadãos, seria mais um fator para o contraste social brasileiro, dando origem ao fenômeno "divisão digital". No Brasil a maior parcela da população vive e trabalha em núcleos urbanos, onde as administrações locais são, em regra, mais próximas de cada indivíduo, para atender a suas demandas e identificar o impacto e as possibilidades de impantar uma $e$ estratégia, uma visão global para aproveitar o potencial das TICs.

De outra parte, a transformação da governança urbana em um capitalismo tardio, permitiu examinar a função do processo urbano, ou seja, a "reestruturação radical em andamento nas distribuições geográficas da atividade humana e na dinâmica políticoeconômica do desenvolvimento geográfico desigual dos tempos mais recentes" (HARVEY, 2005, p. 164). Para realizar este objetivo, Harvey complementa que os governos devem adotar além de responsabilidades administrativas, também atividades empreendedoras.

Nessa senda, as cidades digitais assumem uma dimensão global, passando a exigir a elaboração de estratégias dos governos nacionais e regionais para se criar condições ideais voltadas à inserção das populações na sociedade da informação (CUNHA; MIRANDA, 2013). Todavia, é preciso um enfoque especial quanto ao aspecto da infraestrutura adequada para uma inclusão digital eficaz, não tornando o investimento improfícuo. 
Em relação aos gestores e servidores públicos, estes devem ser capacitados para compreender as cidades inteligentes, por meio de treinamentos sobre Economia Compartilhada, Gestão Pública Colaborativa, Internet das Coisas, Inteligência Artificial, Big Data, Sensoriamento Urbano e Centrais de Monitoramento e Controle.

Outro fator importante são as ações de política econômica na indústria de TIC, que já impacta de forma expressiva o PIB do Brasil (0,88\%), EUA, Japão e Alemanha (próximos a 2\%) (GETIP, 2018). Deste modo, as agências internacionais confirmam que as TICs contribuem para a promoção do desempenho das instituições, da distribuição de serviços, bem como a participação democrática da população no governo, demonstrando além de um impacto econômico, também, um impacto social em sua utilização.

As TICs implementadas no setor público e no setor privado são diferentes, posto que, apesar delas possuírem funções semelhantes, suas abordagens são distintas. Frisese que no aspecto público existe a submissão do governo ao controle externo, exigência inexistente na iniciativa privada.

Diante de todas as especificidades e complexidade que abrangem o desenvolvimento de uma cidade inteligente, as Parcerias Público-Privadas (PPPs), ante o déficit orçamentário brasileiro, se apresentam como uma alternativa interessante para o uso pela Pública Administração disponível no ordenamento jurídico pátrio.

As Parcerias Público-Privadas, como modelos de contratação de empresas privadas para o fornecimento de serviços públicos, onde a empresa fica responsável pelo financiamento, execução e manutenção de infraestruturas físicas e pela prestação de serviço à população, são consideradas um dos melhores caminhos para o alcance do status de Smart Cities (cidades inteligentes), por conta de a transformação de uma cidade em cidade inteligente necessitar de investimentos pesados, considerando o orçamento limitado de cada município. Dessa forma, a PPP emerge como solução, uma vez que o parceiro privado fica responsável em investir recursos, buscando os valores necessários para a implantação do serviço ou obra até a vigência do contrato que não pode ser inferior a 5 anos.

Decerto, os Estados federados e os municípios têm algumas restrições que podem ser sanadas por meio das PPPs. Para o desenvolvimento dos projetos referentes às cidades inteligentes, os entes públicos requerem grandes aportes financeiros que, se fossem contratados normalmente por meio de procedimento licitatório pautado na Lei 
geral de licitação, não haveria como angariar tais recursos orçamentários prontamente. Como os contratos firmados através de PPPS são extensíveis até 35 anos (art. 5, I, da Lei $\left.{ }^{\circ} 11.079 / 2004\right)$, torna-se cabível se firmar PPPs para se captar e implementar ações e obras de grande vulto, no desenvolvimento de serviços inteligentes, onde o Estado, por si só, não teria condições de executá-los e/ou gerí-los (ANTUNES, 2017).

Evidencie-se que diversos são os benefícios oriundos dessa opção pelas parcerias. A Lei 11.079/2004 apresenta alguns, quais sejam: redução das despesas orçamentárias, profissionalização da gestão do serviço, implementação de projetos de grande vulto, possibilidade de remunerar o parceiro privado de acordo com seu desempenho, auxiliando, desta forma, no cumprimento das metas fiscais da Lei de Responsabilidade Fiscal.

Posto isto, as PPPs são caminhos que podem propiciar diversas formas de investimentos, seja de ordem tecnológica ou não, viabilizando desenvolvimento, com base em inovação, de forma mais célere e com qualidade desejada ao que se entende como produtiva e competitiva, em sintonia com o atendimento do interesse público.

\section{CONCLUSÃO}

Em um contexto geral, cada cidade deve determinar a sua própria visão e o seu processo de evolução até a gestão inteligente. Contudo, para alcançar um avanço adequado e eficaz é imprescindível implementar a liderança nos municípios, além de um trabalho conjunto com as demais esferas da administração pública, também com as empresas, as universidades e, especialmente, com os cidadãos.

A economia do futuro será digital e deverá alcançar todos os brasileiros. É incabível conceber uma economia moderna e dinâmica que não propicie a igualdade de oportunidades em todas as regiões do País. A área digital tem se mostrado como um novo centro vital das modernas economias e os países líderes têm se posicionado de forma estratégica em relação ao tema.

Perpassando por um cenário internacional, muitos países objetivam alavancar suas principais competências e vantagens e, ao mesmo tempo, preencherem lacunas relevantes para maximizar os benefícios da economia digital. Evidencie-se que a depender do dinamismo econômico, além das principais forças produtivas, determinados países procuram ser líderes em certos setores promissores, entre eles, a 
robótica, a inteligência artificial, a manufatura de alta precisão ou as inovações financeiras digitais, enquanto os demais gerenciam seus marcos regulatórios de modo a aproveitar o potencial das tecnologias digitais.

As Parcerias Público-Privadas também podem beneficiar na estruturação adequada das cidades inteligentes, uma vez que as PPPs auxiliam no aporte de recursos vultosos, em face do orçamento cada vez mais limitado das cidades.

Devem, também, os países priorizarem as iniciativas de informatização, buscando a competitividade em negócios digitais, mormente quanto aos serviços públicos, gerando empregos qualificados na nova economia e políticas para uma educação melhor e mais avançada.

Nesse contexto, as cidades inteligentes emergem como aquelas que utilizam a tecnologia para promover o bem-estar da população, através da acessibilidade e da sustentabilidade, sem olvidar à melhorida da situação econômica daquela comunidade.

A pesquisa realizada nas plataformas de bases de dados selecionadas, constatou que a comunidade científica brasileira vem estudando e ampliando seus estudos sobre as cidades inteligentes como uma política não mais do futuro, mas do presente, procurando atuar diretamente na economia, na governança, na mobilidade, na acessibilidade, no meio ambiente e na melhoria na condições de vida da sociedade. Pensando nessa melhoria da qualidade de vida é que é preciso desenvolver pesquisas científicas para compreender e aprofundar o tema com vistas a fazer algo de maneira mais eficiente ou eficaz para o desenvolvimento da nação. Nenhum país consegue se desenvolver sem incentivo e investimento em pesquisas acadêmicas.

Os trabalhos encontrados destacam um interesse maior pelo tema nas universidades públicas, 54 estudos oriundos da USP na BDTD e 4 pesquisas com origem na PUC ( SP e RS) na SPELL, demonstrando um interesse maior pelo tema na região sul e sudeste, nas duas bases, e com primazia de publicações no ano de 2019. A área de conhecimento com maior concentração dos trabalhos foi a de administração tanto na BDTD, com 40 pesquisas, quanto na SPELL com 7 artigos.

Espera-se, com este trabalho, contribuir para um melhor entendimento do tema com subsídios para direcionar futuros estudos e se fazer pensar nos problemas reais da sociedade, com o objetivo de torná-la mais dinâmica, acessível, integrada 
tecnologicamente, sustentável economicamente e ecologicamente, com maior mobilidade e governança.

As cidades inteligentes se direcionam para inúmeras possibilidades de crescimento do ser humano no futuro de forma responsável socialmente e ambientalmente. Enfim, como bem defende Martha Gabriel, é preciso criatividade para solucionar situações inéditas, que normalmente requerem experimentação e aceitação de processos de tentativa e erro para gerarem resultados em ambientes com alto risco de incerteza, riscos estes naturais na implementação de uma cidade inteligente, na medida em que a economia nacional pátria deverá concorrer para superar desafios e avançar na digitalização da economia trazendo vantagens competitivas em determinadas áreas, levando o Brasil a superar os desafios que tem à sua frente.

\section{REFERÊNCIAS}

ALPERSTEDT NETO, C. A., Rolt, C. R. de, \& Alperstedt, G. D. (2018). Acessibilidade e Tecnologia na Construção da Cidade Inteligente. Revista de Administração Contemporânea, 22(2), 291-310. https://dx.doi.org/10.1590/19827849rac2018170295. Acesso em: 25 mar. 2019.

ANTUNES, Vitor Amuri. Parcerias Pública-privadas para Smart Cities. Ed. Lumen Juris. São Paulo: 2017.

BANDEIRA DE MELLO, Celso Antônio. Curso de Direito Administrativo Brasileiro. 31. ed. São Paulo: Malheiros Editores, 2014.

BRASIL. Constituição da República Federativa do Brasil de 1988. Disponível em: http://www.planalto.gov.br/ccivil_03/Constituicao/Constituicao.htm. Acesso em: 25 mai. 2019.

BRASIL. Lei no 13.146 de 06 de julho de 2015. Institui a Lei Brasileira de Inclusão da Pessoa com Deficiência (Estatuto da Pessoa com Deficiência). Disponível em: http://www.planalto.gov.br/ccivil_03/_ato2015-2018/2015/lei/113146.htm. Acesso em: 25 mai. 2019.

BRAZILLAB. BrazilLab: Inovação Govtech. 2019. Disponível em: https://brazillab.org.br/noticias/conheca-as-cidades-mais-inteligentes-do-brasil-em2019-segundo-ranking-connected-smart-cities\#. Acesso em: 10 Abr. 2019.

BDTD. Biblioteca Digital Brasileira de Teses e Dissertação. Disponível em: http://bdtd.ibict.br/vufind/. Acesso 2 abr. 2019. 
CONNECTED SMART CITIES. Cidades inteligentes do nordeste. 2018. Disponível em: https://www.connectedsmartcities.com.br/2018/03/13/cidades-inteligentes-donordeste/. Acesso em: 15 Abr. 2019.

CALVILLO, C. F.; SÁNCHEZ-MIRALLES, A.; VILLAR, J. Energy management and planning in smart cities. Renewable and Sustainable Energy Reviews, v. 55, p. 273287, 2016.

CASTELLS, Manuel. A sociedade em rede. 6. ed. São Paulo: Paz e Terra, 2012.

COLOMBO, Jamires Fátima; LUCCA FILHO, João de. Internet das coisas (IOT) e Indústria 4.0. Revista Interface Tecnológica, 2018. Disponível em: https://revista.fatectq.edu.br/index.php/interfacetecnologica/article/view/496. Acesso em: 18 abr. 2019.

CUNHA, Maria Alexandra Viegas Cortez da; MIRANDA, Paulo Roberto de Mello. Uso de TIC pelos Governos: uma proposta de agenda de pesquisa a partir da produção acadêmica nacional. Organizações \& Sociedade, v. 20, n. 66, p. 543-566, 2013. Disponível em: http://www.scielo.br/pdf/osoc/v20n66/10.pdf. Acesso em: 25 mar. 2019.

CUNHA, Maria Alexandra. Smart cities: transformação digital de cidades. São Paulo: Programa Gestão Pública e Cidadania - PGPC, 2016. Disponível em: https://www.researchgate.net/publication/299569472_Smart_cities_transformacao_digit al_de_cidades. Acesso em: 14 abr. 2019.

DELOITTE, Touche Tohmatsu. Insights about Digital Transformation and ICT Opportunities for Brazil Report and Recommendations. January 2019 | Edition $\mathrm{n}^{\mathbf{0}} 2$.

FGV PROJETOS. Cidades Inteligentes e Mobilidade Urbana. Cadernos FGV Projetos, Rio de Janeiro, n. 24, 2014. Disponível em: https://fgvprojetos.fgv.br/publicacao/cadernos-fgv-projetos-no-24-cidades-inteligentese-mobilidade-urbana. Acesso em: 25 mar. 2019.

GABRIEL, Martha. Você, eu e os robôs: pequeno manual do mundo digital. São Paulo: Atlas, 2018.

GETIP. O uso de TIC pelos governos: uma proposta de agenda de pesquisa a partir da produção acadêmica e da prática nacional (Resenha). 02/02/2018. Disponível em: http://getip.net.br/leituras-quase-obrigatorias/o-uso-de-tic-pelos-governos-umaproposta-de-agenda-de-pesquisa-a-partir-da-producao-academica-e-da-pratica-nacionalresenha. Acesso em: 14 abr. 2019.

HARVEY, David. Produção Capitalista do Espaço. São Paulo: Annablume, 2005.

IESE BUSSINESS SCHOOL. Cities in motion: index 2019. Disponível em: https://citiesinmotion.iese.edu/indicecim/. Acesso em: 14 abr. 2019. 
JORDÃO, Kelem Christine Pereira. Cidades inteligentes: uma proposta viabilizadora para a transformação das cidades brasileiras. 2016. 307p. Dissertação (Programa de Pós-Graduação em Sistemas de Infraestrutura Urbana) - Pontifícia Universidade Católica de Campinas, Campinas-SP.

LIBÓRIO, Daniela Campos, SAULE JÚNIOR, Nelson. Princípios e instrumentos de política urbana. Enciclopédia jurídica da PUC-SP. Celso Fernandes Campilongo, Álvaro de Azevedo Gonzaga e André Luiz Freire (coords.). Tomo: Direito Administrativo e Constitucional. Vidal Serrano Nunes Jr., Maurício Zockun, Carolina Zancaner Zockun, André Luiz Freire (coord. de tomo). 1. ed. São Paulo: Pontifícia Universidade Católica de São Paulo, 2017. Disponível em: https://enciclopediajuridica.pucsp.br/verbete/76/edicao-1/principios-e-instrumentos-depolitica-urbana. Acesso em: 16 abr. 2019.

LAZZARETTI , K. ET AL. Cidades inteligentes: insights e contribuições das pesquisas brasileiras. Revista Brasileira de Gestão Urbana, 2019.

MAKISHI, Márcia. Afinal o que Significa Compliance?. Disponível em: https://administradores.com.br/noticias/afinal-o-que-significa-compliance. Acesso em 18 jun. 2019.

MANSO, Leonardo Briza Paes. Cidades sustentáveis e inteligentes: tecnologias colaborativas de apoio à gestão urbana. 2020. 199p. Dissertação (Programa de PósGraduação em engenharia Civil) - Universidade e São Paulo.

MEDINA, Paloma Fraga; KRAWULSKI, Edite. Coworking como modalidade e espaço de trabalho: uma análise bibliométrica. Cadernos de Psicologia Social do Trabalho, v. 18, n. 2, p. 181-190, 2015.

NALINI, José Renato; LEVY, Wilson. Cidades Inteligentes e sustentáveis: desafios conceituais e regulatórios. Revista de Direito da Administração Pública, Rio de Janeiro, ano 02, v. 02, ed. 1 - jan-dez, p. 184-201, 2017.

SPELL. Scientific Periodicals Electronic Library. Disponível em: http://www.spell.org.br/. Acesso em 2 abr. 2019.

SOUZA, Edileusa Godói de.; LOPES, José Eduardo Ferreira. Empreendedorismo tecnológico e startups: uma análise de cenários no contexto de universidades brasileiras. Disponível em: https://www.egepe.org.br/2016/artigos-egepe/154.pdf. Acesso em: 16 abr. 2019.

SOBRAL DE SOUZA, Patrícia Verônica Nunes Carvalho; SOARES, Ricardo Maurício Freires. A influência do Big Data no Controle Social da Gestão Pública. Revista de Direitos Humanos Fundamentais, v. 2, p. 83-107, 2019.

STRAPAZZON, Carlos Luiz. Convergência tecnológica nas políticas urbanas: pequenas e médias “cidades inteligentes". Revista Juridica, [S.1.], v. 22, n. 6, p. 89108, jun. 2009. ISSN 2316-753X. Disponível em: 
<http://revista.unicuritiba.edu.br/index.php/RevJur/article/view/104/80>. Acesso em: 23 abr. 2020. doi:http://dx.doi.org/10.21902/revistajur.2316-753X.v22i6.104.

TELLES, Marcelo Josué; BARBOSA, Jorge Luis Victória; RIGHI, Rodrigo da Rosa. Um Modelo Computacional para Cidades Inteligentes Assistivas. Revista Brasileira de Sistemas de Informação, Rio de Janeiro, v. 10, n. 1, p. 52-79, 2017.

UNESCO. E-Governance. Disponível em: http://portal.unesco.org/ci/en/ev.phpURL_ID=3038\&URL_DO=DO_TOPIC\&URL_SECTION=201.html. Acesso em: 14 abr. 2019.

UN-HABITAT. Planning and Design for Sustainable Urban Mobility: Global Report on Human Settlements, 2013. Disponível em: http://unhabitat.org/planning-and-designfor-sustainable-urban-mobility-global-report-on-human-settlements-2013/. Acesso em: 18 abr. 2019.

WEISS, M.C.; BERNARDES, R. C.; CONSONI, F. L. Cidades inteligentes como nova prática para o gerenciamento dos serviços e infraestruturas urbanos: a experiência da cidade de Porto Alegre. Revista Brasileira de Gestão Urbana (Brazilian Journal of Urban Management), 2015. 